\title{
Mushroom-based cosmeceutical ingredients: Microencapsulation and in vitro release profile
}

\author{
Oludemi Taofiq ${ }^{\mathrm{a}, \mathrm{b}, \mathrm{c}}$, Sandrina A. Heleno ${ }^{\mathrm{a}, \mathrm{b}}$, Ricardo C. Calhelha ${ }^{\mathrm{a}}$, Isabel P. Fernandes ${ }^{\mathrm{a}, \mathrm{b}}$, \\ Maria José Alves $^{\mathrm{a}}$, Lillian Barros ${ }^{\mathrm{a}}$, Ana M. González-Paramás ${ }^{\mathrm{c}}$, Isabel C.F.R. Ferreira ${ }^{\mathrm{a}, *}$, \\ Maria F. Barreiro ${ }^{a, b, *}$ \\ a Centro de Investigação de Montanha (CIMO), Instituto Politécnico de Bragança, Campus de Santa Apólónia, 5300-253 Bragança, Portugal \\ ${ }^{\mathrm{b}}$ Laboratory of Separation and Reaction Engineering (LSRE), Associate Laboratory LSRE/LCM, Polytechnic Institute of Bragança, Campus de Santa Apolónia, 1134, \\ 5301-857 Bragança, Portugal \\ ${ }^{c}$ GIP- USAL, Unidad de Nutrición y Bromatología, Faculty of Pharmacy, University of Salamanca, Campus Miguel de Unamuno, 37007 Salamanca, Spain
}

\section{A R T I C L E I N F O}

\section{Keywords:}

Mushroom extracts

Cosmeceuticals

Bioactive properties

Microencapsulation

Controlled release

\begin{abstract}
A B S T R A C T
Mushrooms can be used as a source of cosmeceutical ingredients. Agaricus bisporus and Pleurotus ostreatus ethanolic extracts present important bioactive properties, but with some compounds showing easy oxidation and degradation. In the present work, microencapsulation by atomization/coagulation technique was used to protect the extracts. The obtained microspheres were characterised in terms of morphology, particle size distribution and encapsulation efficiency. Microencapsulated extracts were incorporated into a semi-solid base cream and their performance compared with the use of the free forms in terms of bioactivity, and in vitro release using the cosmetic matrix and real time conditions (up to 6 months). The physico-chemical properties (colour and $\mathrm{pH}$ ) of the developed formulations were also monitored over the same time period. The cosmeceutical formulations containing free extracts displayed bioactivity. For the formulations prepared with the encapsulated forms, the release of the extracts was achieved and anti-tyrosinase and antimicrobial activities were observed, while for the antioxidant activity, the extract release over the time was not sufficient to exert an effect. Overall, the use of mushroom extracts in free or encapsulated forms can be an option in cosmeceutical formulations, and the encapsulated forms can allow a controlled release leading to bioactivity control.
\end{abstract}

\section{Introduction}

Due to consumer's demands, safety of synthetic chemicals, and environmental limitations, personal care and cosmetic formulators are increasingly interested in bioactive ingredients, namely those obtained from natural sources with environmental friendly connotations, and less toxic effects (Secchi et al., 2014). Natural additives such as phytonutrients, algae and microbial metabolites, dairy products, minerals and animal protein components are becoming increasingly applied in cosmeceutical formulations (Taofiq et al., 2016a). The term cosmeceutical was first coined by Albert Kligman, over 30 years ago at the National Scientific Meeting of the Society of Cosmetic Chemists, and this emerging concept refers to the use of bioactive compounds with drug like benefits either to improve skin appearance, suppress hyperpigmentation and provide anti-aging benefits (Bissett, 2009). The cosmeceutical market in recent years has identified several compounds from natural sources with potential to be used as cosmeceutical ingredients (Taofiq et al., 2016a). The most widely used bioactive compounds are those that display multifunctional properties mainly antioxidant, tyrosinase, collagenase and elastase inhibitors (Miyake et al., 2010; Taofiq et al., 2017b, 2016b).

Mushrooms have been gaining a progressive importance in our diet due to their rich nutritional composition and low caloric value. Furthermore, mushrooms exert health promoting benefits derived from their antioxidant, antitumour, antimicrobial, anti-inflammatory, antityrosinase, immunomodulator, antiatherogenic and hypoglycemic activities, which can be attributed to different bioactive compounds in their composition (e.g., phenolic compounds, terpenoids, polysaccharides, lectins, steroids, glycoproteins and lipids) (Heleno et al., 2012; Reis et al., 2015; Taofiq et al., 2016c, 2015). Their use in the development of nutraceuticals, alternative medicines and drug discovery (Bishop et al., 2015; Money, 2016) have been extensively

\footnotetext{
* Corresponding authors at: Centro de Investigação de Montanha (CIMO), Instituto Politécnico de Bragança, Campus de Santa Apólónia, 5300-253 Bragança, Portugal.

E-mail addresses: iferreira@ipb.pt (I.C.F.R. Ferreira), barreiro@ipb.pt (M.F. Barreiro).
} 
exploited, with their cosmeceutical significance gaining, gradually, attention (Taofiq et al., 2017b, 2016a,b). According to a recent review conducted by Taofiq et al. (2016a), mushrooms demonstrated high potential to be used as cosmeceutical ingredients, with some commercial products still referring the use of mushrooms extracts, alone or in combination with other natural extracts/ingredients.

The use of natural ingredients by the cosmetic industry has been encouraged in the past years; nevertheless, the incorporation of these bioactive ingredients during product formulation can face several limitations, namely instability due to the interference with other compounds, sensitivity to $\mathrm{pH}$ and temperature, or propensity to degradation, which will result in the gradual loss of efficiency and effectiveness along time (Casanova et al., 2016). To overcome such constraints, several nano- and micro-technologies have been applied to design efficient delivery systems, not just in the cosmetic sector but also in the food and pharmaceutical ones. Microencapsulation techniques employ the use of polymeric materials to protect active principles (e.g. active ingredients), conferring protection, thus improving stability, and/or provide their gradual release over the time, assuring therapeutic treatments at correct concentrations and at the target sites (dos Santos et al., 2016). Biodegradable polymers such as poly( $\mathcal{E}$-caprolactone) (PCL), polylactic acid (PLA) poly-D, L-lactide-co-glycolide (PLGA), chitosan, and diverse polysaccharides have been used to encapsulate components such as vitamins, phenolic compounds, essential oils, pigments and fragrances (dos Santos et al., 2016). Even though bioactive compounds have been successfully microencapsulated using a wide range of polymeric materials, real-time in vitro release of the microparticles often require runs over long time-periods, ranging from days, weeks, months or even years. This has increased studies relating to finding efficient methods to accelerate in vitro release studies of these microencapsulated ingredients (Andhariya et al., 2017a).

Following recent studies conducted by Taofiq et al. (2016b), where ethanolic extracts of Agaricus bisporus (J.E. Lange) Imbach, Lentinula edodes (Berk.) Pegler and Pleurotus ostreatus (Jacq. ex Fr.) P. Kumm) demonstrated cosmeceutical potential, A. bisporus and $P$. ostreatus, due to their highest bioactivity, were selected to be used in the present study. Thus, ethanolic extracts obtained from these mushroom species were prepared and further microencapsulated by the atomization/ coagulation method with sodium alginate as the polymeric matrix. The produced microspheres were fully characterised and thereafter incorporated in a base cosmetic cream. The bioactive and physicochemical properties imparted by these microencapsulated extracts, comparatively with the use of the respective free forms, were evaluated over a 6 months' time period. These studies were performed to ascertain stability of the prepared formulations, microencapsulated versus free forms, and monitor the in vitro release profile of selected bioactive compounds (phenolic acids and ergosterol) in base-cream formulations.

\section{Materials and methods}

\subsection{Standards and reagents}

Acetonitrile $99.9 \%$ was of high-performance liquid chromatography (HPLC) grade from Lab-Scan (Lisbon, Portugal), methanol was of analytical grade and supplied by Pronalab (Lisbon, Portugal). 2, 2Diphenyl-1-picrylhydrazyl (DPPH) was obtained from Alfa Aesar (Ward Hill, MA, USA). Dulbecco's modified Eagle's minimum essential medium (DMEM), $p$-hydroxybenzoic, $p$-coumaric, protocatechuic and cinnamic acids, fetal bovine serum (FBS), penicillin, streptomycin, Griess reagent system (Promega), DMSO, sulphorodamine B (SRB), lipopolysaccharide (LPS), 3,4-dihydroxy-L-phenylalanine (L-DOPA) and mushroom tyrosinase enzyme were obtained from Sigma-Aldrich Co. (Saint Louis, MO, USA). Sodium alginate was provided by Fluka Chemie (USA), calcium chloride and Tween 80 by Panreac (Spain). Muller Hinton broth (MHB) and Tryptic Soy Broth (TSB) culture media were obtained from Biomerieux (Marcy l'Etoile, France). Blood agar (7\% sheep blood), and MacConkey agar plates were purchased from Biomerieux Marcy l'Etoile, France). The $p$-iodonitrotetrazolium chloride (INT) was purchased from Sigma-Aldrich (Spruce Street; St. Louis, MO, USA) being used as microbial growth indicator.

\subsection{Mushroom species and preparation of ethanolic extracts}

Fresh samples of A. bisporus and P. ostreatus were purchased from a local supermarket in Bragança at the Northeast of Portugal. For each mushroom species, the fruiting bodies were dried at $30^{\circ} \mathrm{C}$ in an oven and reduced to a fine powder $(20$ mesh) for further extraction and analysis. Extraction was performed in a Soxhlet apparatus using $3.0 \mathrm{~g}$ of the dried powder per $150 \mathrm{~mL}$ of ethanol during 5-6 h. Thereafter, the solvent was evaporated under reduced pressure (rotary evaporator Büchi R-210, Flawil, Switzerland) to obtain dried ethanolic extracts.

\subsection{Microencapsulation of the extracts}

\subsubsection{Microencapsulation procedure}

The atomization/coagulation technique was employed to microencapsulate the A. bisporus and P. ostreatus extracts, similarly to the protocol reported by Caleja et al. (2017) with slight modifications. Sodium alginate, in combination with calcium chloride $\left(\mathrm{CaCl}_{2}\right)$, was used. The microspheres were produced as follows: $100 \mathrm{mg}$ of the extract were suspended in $20 \mathrm{~mL}$ of distilled water in the presence of $100 \mathrm{mg}$ of tween 80 as surfactant. The mixture was then homogenised for $20 \mathrm{~min}$ using a Unidrive X100 homogenizer (Ingenieurbüro CAT, Germany). Afterwards, $400 \mathrm{mg}$ of sodium alginate was added to the suspension, keeping this mixture under stirring until complete dissolution of alginate. The produced solution was atomized in the NISCO Var J30 system (Zurich, Switzerland) at a flow rate of $0.3 \mathrm{~mL} / \mathrm{min}$ and a nitrogen pressure of $100 \mathrm{mbar}$ (Fig. 1). The atomized droplets were coagulated by contacting with the aqueous solution of $\mathrm{CaCl}_{2}(250 \mathrm{~mL}$, concentration of $4 \%(\mathrm{w} / \mathrm{v}))$ over a time-period of $4 \mathrm{~h}$. The produced microspheres were then recovered by filtration under reduced pressure, washed twice with distilled water, and finally lyophilized and stored in the dark conditions at $4{ }^{\circ} \mathrm{C}$. For easy identification of the samples, the following codes were assigned to each microparticle denoting the ingredient that they contain: A- $A$. bisporus extract, P- P. ostreatus extract and E- empty microparticles.

\subsubsection{Microencapsulation efficiency, yield and load}

Encapsulation efficiency (EE \%): This parameter measures the ability of the encapsulating material to properly encapsulate the bioactive ingredient and can be achieved by analyzing the amount that has not been encapsulated (in the present case, the cumulative amount of extract present in the coagulation solution and in the first washing solution) with respect to the theoretical amount calculated based on the used formulation. Quantification was done by HPLC coupled to a photodiode array detector (PDA) (Papadimitriou and Bikiaris, 2009). The encapsulation efficiency was thereafter calculated using the following expression:

$\mathrm{EE}(\%)=\frac{\text { weight of the encapsulated bioactive }}{\text { total weight of bioactive used in the formulation }} \times 100$

Encapsulation yield: This parameter compares the total weight of the produced microcapsules relative to the total weight of the atomized material, being calculated using the following expression:

$\mathrm{EY}(\%)=\frac{\text { weight of produced micropheres }}{\text { weight of the atomized formulation }} \times 100$

Encapsulation load: This parameter measures the bioactive content $(\%, \mathrm{w} / \mathrm{w})$ present in the produced microspheres and can be calculated as follows: 


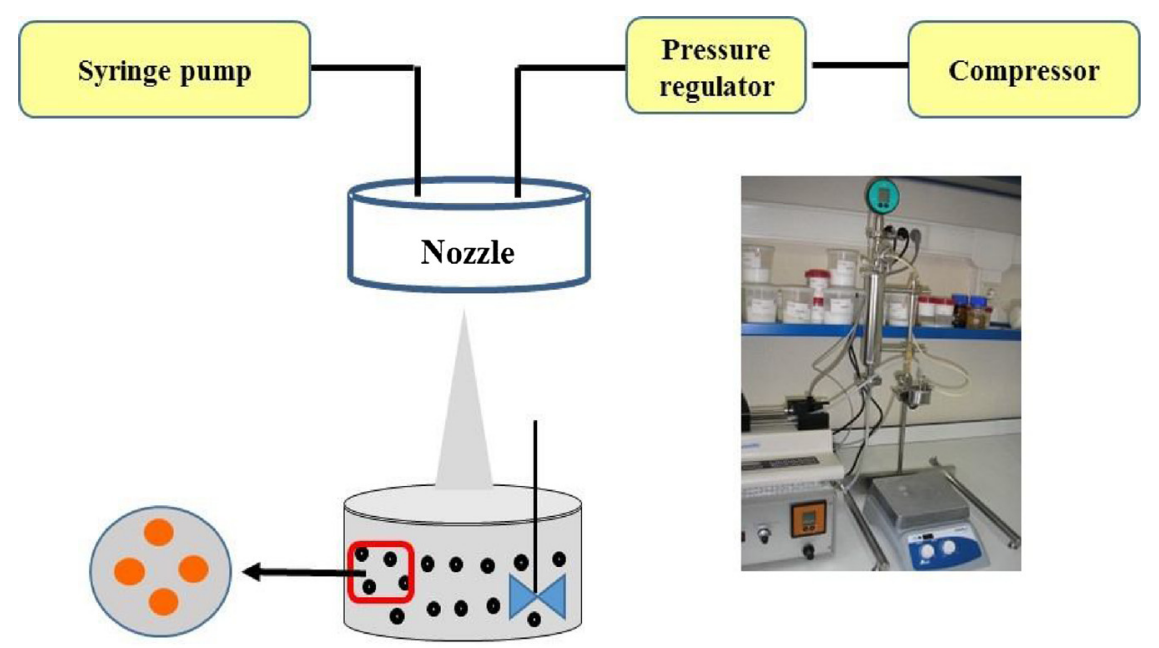

\section{Alginate matrix with bioactive extract dispersed}

Fig. 1. Nisco Var J30 microencapsulation unit used for microparticles preparation.

$\mathrm{EL}(\%)=\frac{\text { weight of the encapsulated bioactive }}{\text { weight of the produced micropheres }} \times 100$

\subsubsection{Microcapsules characterization}

Microspheres were analysed by optical microscopy (OM) using a Nikon Eclipse 50i microscope (Tokyo, Japan) equipped with a Nikon Digital Sight camera and NIS Elements software for data acquisition. OM analysis was applied to assess the size and morphology of the microspheres right after the atomization and during the coagulation stage.

The particle size distributions were determined by laser diffraction using a Malvern Mastersizer 3000 laser equipped with a Hydro MV dispersion unit (Malvern, UK). Data was obtained and treated with Mastersizer software version 3.10. Water was used as the solvent for sample dispersion. Five measurements were made to ensure reproducibility, and the results were expressed in volume and number, being particle size results expressed as the percentiles of $10 \%, 50 \%$ and $90 \%$. The residual values were less than $1 \%$. The span of the volume-based size distribution was also determined using the expression (Dv90Dv10)/Dv50 (Barboza et al., 2014).

\subsection{Development of the cosmeceutical formulations}

A cosmetic and white cream, free from fragrances, colourants, parabens, mineral oils, sodium lauryl sulphate (SLS), propylene glycol, and ethoxylates, purchased from Fagron Iberica S.A.U. (Barcelona, Spain) was used. According to the technical data available, this formulation has been certified to be safe by the US Food and Drug Administration (FDA), Regulation (EC) No 1907/2006-REACH and the National Health Surveillance Agency (ANVISA) of Brazil.

In order to cover the magnitude of all the bioactive properties to be evaluated, the base creams were incorporated at a content of 2.5-fold the $\mathrm{EC}_{50}$ and MIC values of the free extracts (Table A1, Supplementary material) which correspond to a scale of $25 \mathrm{mg}$ of extract per gram of base cream. The extracts, and the prepared microcapsules, were individually formulated into the base cosmetic cream, using continuous stirring until the mixture was fully homogenized. The formulations were stored in tightly closed vials at $4{ }^{\circ} \mathrm{C}$ with samples withdrawn periodically (up to 6 months) to determine the evolution of the bioactive properties and changes in physicochemical parameters.

\subsection{Evaluation of the bioactive properties of the developed cosmeceutical formulations}

For bioactivity evaluation, the prepared cosmeceutical formulations were dissolved in a solution of $50 \%(\mathrm{v} / \mathrm{v})$ DMSO at $400 \mathrm{mg} / \mathrm{mL}$ for antioxidant activity, and at $100 \mathrm{mg} / \mathrm{mL}$ for anti-tyrosinase activity evaluation. For antibacterial activity evaluation, a 5\% (v/v) DMSO solution was used, and the concentration was $400 \mathrm{mg} / \mathrm{mL}$.

\subsubsection{Antioxidant activity}

Solutions with concentrations ranging from 25 to $400 \mathrm{mg} / \mathrm{mL}$ were prepared from the stock solution of $400 \mathrm{mg} / \mathrm{mL}$ described previously. Two assays were used: DPPH scavenging activity and reducing power.

DPPH scavenging activity: For each cream formulation, $30 \mu \mathrm{L}$ of each prepared dilution were mixed with $270 \mu \mathrm{L}$ of methanol containing DPPH radicals $\left(6 \times 10^{-5} \mathrm{~mol} / \mathrm{L}\right)$. The mixture was allowed to stand in the dark for $1 \mathrm{~h}$. The absorbance was measured at $515 \mathrm{~nm}$ in a microplate reader (ELX800 Bio-Tek Instruments, Inc.). The radical scavenging activity (RSA) was calculated using the equation: \% RSA = $\left[\left(A_{D P P H}-A_{S}\right) / A_{D P P H}\right] \times 100$, where $A_{S}$ is the absorbance of the sample solution and $A_{D P P H}$ is the absorbance of the DPPH solution. The concentrations responsible for $50 \%$ of RSA ( $\mathrm{EC}_{50}$ values) were calculated from the graphical representation of RSA percentage versus extract concentration. Trolox was used as the positive control.

Reducing power: Samples of the prepared dilutions $(0.5 \mathrm{~mL})$ were mixed with sodium phosphate buffer $(200 \mathrm{mmol} / \mathrm{L}, \mathrm{pH} 6.6,0.5 \mathrm{~mL})$ and potassium ferricyanide $(1 \% \mathrm{w} / \mathrm{v}, 0.5 \mathrm{~mL})$, and further incubated at $50{ }^{\circ} \mathrm{C}$ for $20 \mathrm{~min}$. Trichloroacetic acid $(10 \% \mathrm{w} / \mathrm{v}, 0.5 \mathrm{~mL})$ was added and $0.8 \mathrm{~mL}$ of the mixture was transferred to a 48 -well plate, followed by the addition of deionized water $(0.8 \mathrm{~mL})$, ferric chloride $(0.1 \% \mathrm{w} / \mathrm{v}$, $0.16 \mathrm{~mL})$. Finally, the absorbance was measured at $690 \mathrm{~nm}$ in the above-mentioned microplate reader. The concentrations responsible for $50 \%$ of antioxidant activity ( $\mathrm{EC}_{50}$ values) were calculated.

\subsubsection{Anti-tyrosinase activity}

Tyrosinase inhibition assay was performed using L-DOPA as substrate according to the procedure described by Taofiq et al. (2016b). The assay was carried using a 96-well microplate and solutions prepared from the stock solution of $100 \mathrm{mg} / \mathrm{mL}(100-12.25 \mathrm{mg} / \mathrm{mL})$. Each well was filled with $40 \mu \mathrm{L}$ of the prepared solutions, $80 \mu \mathrm{L}$ of a phosphate buffer ( $0.1 \mathrm{M}, \mathrm{pH} 6.8), 40 \mu \mathrm{L}$ of tyrosinase enzyme (60 units $/ \mathrm{mL}$ ), and $40 \mu \mathrm{L}$ of L-DOPA $(3.5 \mathrm{mM})$. The mixture was incubated for $10 \mathrm{~min}$ at $37^{\circ} \mathrm{C}$, and the absorbance measured at $475 \mathrm{~nm}$ using the aforesaid 
microplate reader. Each sample was accompanied by a blank containing all components except L-DOPA. The results were compared with a control consisting of $50 \%$ DMSO in place of the sample. The percentage of tyrosinase inhibition was calculated as follows: $\left[\left(\mathrm{A}_{\text {control }}-\mathrm{A}_{\text {sample }}\right) /\right.$ $\left.A_{\text {control }}\right] \times 100$. L-Ascorbic acid was used as the positive control.

\subsubsection{Antimicrobial activity}

2.5.3.1. Selected microbial strains. The bacterial strains were clinical isolates obtained from patients hospitalized in various departments at the Hospital Center of Trás-os-Montes and Alto Douro (Vila Real, Portugal). Two Gram-negative bacteria (Escherichia coli and Proteus mirabilis (isolated from urine), three Gram-positive bacteria (Enterococcus faecalis (isolated from urine), methicillin-sensitive Staphylococcus aureus (MSSA) (isolated from wound exudate), and methicillin-resistant Staphylococcus aureus (MRSA) (isolated from expectoration)), and a yeast, Candida albicans (isolated from urine) were tested. All these microorganisms were incubated at $37^{\circ} \mathrm{C}$ in appropriate fresh medium for $24 \mathrm{~h}$ before analysis in order to maintain the exponential growth phase.

2.5.3.2. Determination of the Minimal Inhibitory Concentration (MIC). The determination of the minimal inhibitory concentration (MIC) was performed by the microdilution method and the rapid $p$ iodonitrotetrazolium chloride (INT) colorimetric assay as reported by Taofiq et al. (2016b). The cosmeceutical formulations were dissolved in an aqueous DMSO solution (50\%) followed by the addition of the required medium (TSB or MHB, according to the bacteria requirements), making a solution of $400 \mathrm{mg} / \mathrm{mL}$ at $5 \%$ DMSO. Then, $190 \mu \mathrm{L}$ of this solution were added to each well of the 96 -well microplate and therefore submitted to successive dilutions over the wells containing $90 \mu \mathrm{L}$ of MHB or TSB media. Then, $10 \mu \mathrm{L}$ of inoculum $\left(1.5 \times 10^{8} \mathrm{CFU} / \mathrm{mL}\right)$ were added to all the microplate wells. The plates were then incubated at $37^{\circ} \mathrm{C}$, for $24 \mathrm{~h}$, in an oven (Jouan, Berlin, Germany). The MIC values were determined after adding INT $(0.2 \mathrm{mg} /$ $\mathrm{mL}, 40 \mu \mathrm{L}$ ) followed by incubation at $37^{\circ} \mathrm{C}$ for $30 \mathrm{~min}$. Viable microorganisms reduced the yellow dye to a pink colour. MIC was defined as the lowest extract concentration that prevented this change, thus showing inhibition of bacterial growth.

\subsection{Chemical characterization of the mushroom-based cosmeceutical formulations}

The cream formulations were subjected to extraction with methanol for $30 \mathrm{~min}$, filtered, dried in a rotary evaporator, and re-dissolved in a water:methanol mixture $(80: 20, \mathrm{v} / \mathrm{v})$. The samples were further filtered through a $0.22 \mu \mathrm{m}$ nylon disposable filter and then analysed by ultrafast liquid chromatography (UFLC), model Shimadzu $20 \mathrm{~A}$ series (Shimadzu Corporation, Kyoto, Japan) coupled to a PDA detector, for phenolic acids identification and quantification. For ergosterol identification, the cosmeceutical formulations were directly dissolved in methanol and filtered through a $0.22 \mu \mathrm{m}$ nylon disposable filter and then analysed by HPLC-UV (Knauer, Smartline system 1000, Berlin, Germany). For easy identification of the samples, the following codes were assigned to each cosmeceutical formulation denoting the contained ingredient: BCAb- base cream with A. bisporus extract, BCPobase cream with $P$. ostreatus extract, BCMAb- base cream with microparticles of $A$. bisporus extract, BCMPo- base cream with microparticles of $P$. ostreatus extract, BCEM- base cream with empty microparticles (control), BC- base cream (control).

\subsection{Physico-chemical parameters of the mushroom-based cosmeceutical formulations}

\subsubsection{Colour evaluation}

The colour evaluation of the cosmeceutical formulation was performed using a colourimeter model CR-400 (Konica Minolta Sensing Inc., Tokyo, Japan) that has been calibrated against a standard white tile as described by Caleja et al. (2016). The colour was measured using the $L^{*} a^{*} b^{*}$ system where $l^{*}$ is a measure of the lightness, $a^{*}$ is a measure of the greenness/redness while $b^{*}$ is a measure of the blueness/yellowness. Colour space values were registered using the data software "Spectra Magic Nx" (version CM-S100 W 2.03.0006)

\subsection{2. $p H$ and odour evaluation}

The $\mathrm{pH}$ of each cosmeceutical formulation was evaluated directly with a HI 99,161 pH-meter (Hanna Instruments, Woonsocket, Rhode Island, USA), calibrated before each measurement. The samples were also submitted to olfactory analysis using the human nose as the odour detector, since there is no analytical technique that can completely replace the human nose.

\subsection{Statistical analysis}

For all experiments concerning bioactive properties, chemical composition and physicochemical properties, samples were analysed in triplicate. The results are expressed as mean values \pm standard deviation (SD). The differences among different samples were analysed using one-way analysis of variance (ANOVA) followed by Tukey's honestly significant difference post hoc test with $\alpha=0.05$, coupled with Welch's statistic. This treatment was carried out using SPSS v. 22.0 program.

\section{Results and discussion}

\subsection{Microencapsulation of the extracts}

Table 1 summarizes the results obtained for the encapsulation efficiency, yield, and load. The concentration of the phenolic acids and related compounds in the coagulation and washing solutions was determined to calculate the EE (\%), conducting to values of 72.81 and $99.63 \%$ for A and P, respectively, corroborating the successful encapsulation of the extracts. The EY (\%), which represent the effectiveness of the process, conducted to values of 60.20 and $50.80 \%$ for A and $\mathrm{P}$, which might be considered satisfactory considering that the technique was applied at a laboratory scale. The EL\%, which depicts the content of bioactive in the microparticles was $14.56 \%$ and $19.92 \%$ for A

Table 1

Comparison of particle size distribution in terms of number and volume, encapsulation efficiency, load and yield of the microparticles prepared using alginate.

\begin{tabular}{|c|c|c|c|c|c|c|c|c|c|c|c|c|}
\hline \multirow[t]{3}{*}{ Samples } & \multirow[t]{3}{*}{$\mathrm{EE}(\%)$} & \multirow[t]{3}{*}{ EL (\%) } & \multirow[t]{3}{*}{ EY (\%) } & \multicolumn{7}{|c|}{ Particle size distribution } & \multicolumn{2}{|c|}{ Mean particle size $(\mu \mathrm{m})$} \\
\hline & & & & \multicolumn{4}{|c|}{ Volume distribution } & \multicolumn{3}{|c|}{ Number distribution } & \multirow[t]{2}{*}{ Volume } & \multirow[t]{2}{*}{ Number } \\
\hline & & & & $\mathrm{D}_{10}(\mu \mathrm{m})$ & $\mathrm{D}_{50}(\mu \mathrm{m})$ & $\mathrm{D}_{90}(\mu \mathrm{m})$ & Span & $\mathrm{D}_{10}(\mu \mathrm{m})$ & $\mathrm{D}_{50}(\mu \mathrm{m})$ & $\mathrm{D}_{90}(\mu \mathrm{m})$ & & \\
\hline A & 72.81 & 14.56 & 60.20 & 27.10 & 100.00 & 254.00 & 2.27 & 0.72 & 0.94 & 2.05 & 122.22 & 1.14 \\
\hline$P$ & 99.63 & 19.92 & 55.00 & 27.70 & 94.70 & 240.00 & 2.24 & 0.72 & 0.92 & 1.96 & 109.66 & 1.11 \\
\hline$E$ & na & na & 60.00 & 19.50 & 79.20 & 235.00 & 2.72 & 0.82 & 1.15 & 2.83 & 102.38 & 1.50 \\
\hline
\end{tabular}

na: not applied; EE-encapsulation efficiency; EL-encapsulation load; EY-encapsulation yield. 

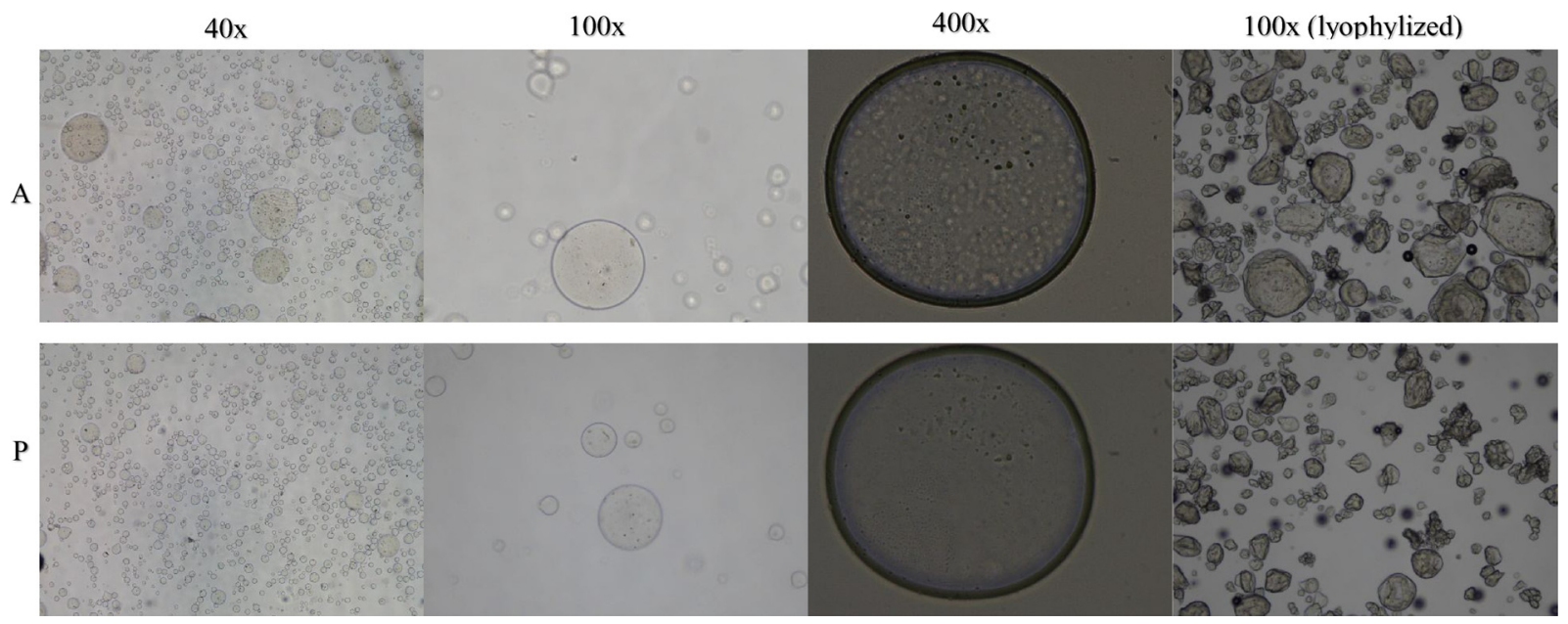

Fig. 2. Optical Microscopy analysis with magnifications of 40, 100 and 400x of the microspheres after $4 \mathrm{~h}$ of coagulation under stirring. with $\mathrm{A}$, and $\mathrm{P}$ representing samples prepared with $A$. bisporus and $P$. ostreatus respectively.

and $\mathrm{P}$, respectively. It allows to determine the quantity of microspheres needed to be incorporated in the semi solid base cream.

The surface morphology of the prepared microparticles, immediately after production, was visualized by optical microscopy and the respective images (acquired at magnifications of 40x, 100x and 400x) are shown in Fig. 2. It is possible to observe a consistent spherical morphology with few particles displaying crumpled shapes of various sizes (consistent with a polydisperse sample), and no agglomeration. The lyophilized microspheres were rehydrated in distilled water and analysed again (magnification of 100x). The final shape of the rehydrated microspheres was quite irregular, but despite their deformation, the final size was close to that obtained immediately after encapsulation.

The results for the particle size distributions, in number and volume, represented in terms of percentiles $\left(D_{10}, D_{50}\right.$ and $\left.D_{90}\right)$ are presented in Table 1 . The respective average particle size (in number and volume) are also presented in Table 1 . The achieved average sizes in volume for A, P and E were 122.22, 109.66 and $102.38 \mu \mathrm{m}$ respectively. From the analysis of the particle size distributions shown in Fig. 3, distributions in number were unimodal (or proximately unimodal), whereas distributions in volume showed a bimodal pattern. Considering span (dispersity) parameter which reveals how homogenous the particle's size is (Table 1), there is no significant dissimilarity among all three produced types of microparticles.

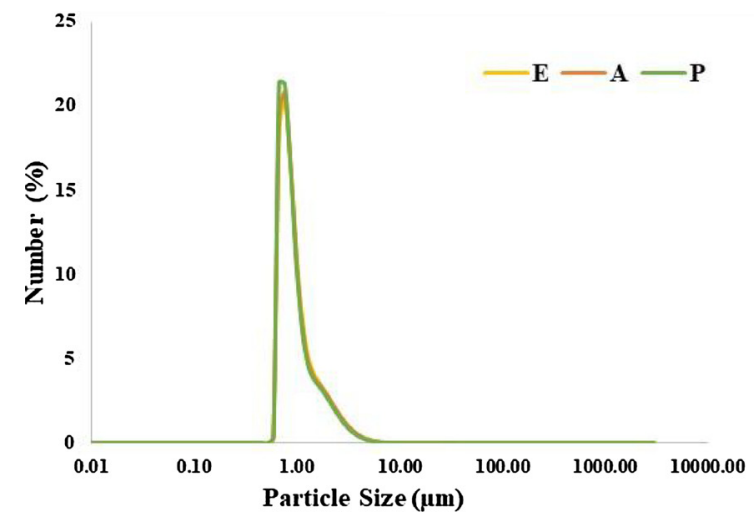

3.2. Bioactivity of mushroom-based cosmeceutical formulations - use of free forms

In the present work, the cosmeceutical potential of each prepared formulation was investigated based on their ability to display antioxidant, anti-tyrosinase and antimicrobial activities. The in vitro antioxidant activity of the cosmeceutical formulations prepared with the ethanolic extracts are presented in Table 2. The formulations revealed both DPPH scavenging activity and reducing power. The antioxidant activity decreased over the time, which can be partly attributed to the oxidation of the extracts. A similar study was reported by Gezina et al. (2015) in which the authors prepared semi-solid formulations containing two species of Honey bush (Cyclopia maculata Vent and Cyclopia genistoides Vent). The active bioflavonoids present in their hydromethanolic extracts were found to lack sufficient stability in semi-solid formulations to sustain the antioxidant activity. The phenolic acids, and related compounds composing the ethanolic extracts of $P$. ostreatus and A. bisporus are listed in Table A2 (Supplementary material) (Taofiq et al., 2016b). These compounds have been reported to contribute significantly to the antioxidant activity (Heleno et al., 2015). The quantification of these compounds in the corresponding semisolid formulations are presented in Table 2. For the cosmeceutical formulations prepared with $A$. bisporus extract (BCAb), and $P$. ostreatus extract (BCPo), phenolic acids, related compounds and ergosterol revealed no significant changes in their content over the storage time (6 months). Considering that there was no significant loss of bioactive compounds under the used storage temperature $\left(4^{\circ} \mathrm{C}\right)$, further studies are needed to

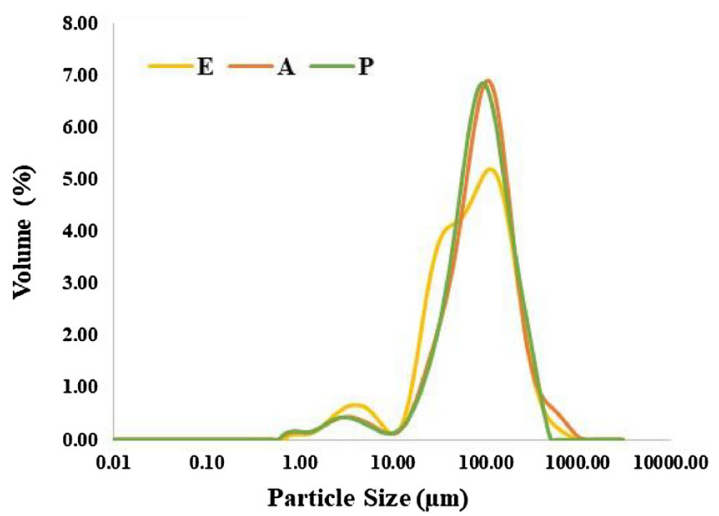

Fig. 3. Microparticles size distributions expressed as mean number distributions and volume distribution, with A, P and E representing samples prepared with A. bisporus, $P$. ostreatus and empty microparticles respectively. 
Table 2

Bioactive properties of the developed cosmeceutical formulations.

\begin{tabular}{|c|c|c|c|c|c|c|c|c|c|}
\hline \multirow[t]{3}{*}{ Creams } & \multirow{2}{*}{\multicolumn{3}{|c|}{$\begin{array}{l}\text { Anti-tyrosinase activity } \\
\mathrm{EC}_{50} \text { values }(\mathrm{mg} / \mathrm{mL})\end{array}$}} & \multicolumn{6}{|c|}{$\begin{array}{l}\text { Antioxidant activity } \\
\mathrm{EC}_{50} \text { values }(\mathrm{mg} / \mathrm{mL})\end{array}$} \\
\hline & & & & \multicolumn{3}{|l|}{$\mathrm{DPPH}$} & \multicolumn{3}{|c|}{ Reducing power } \\
\hline & Time 0 & Time 3 & Time 6 & Time 0 & Time 3 & Time 6 & Time 0 & Time 3 & Time 6 \\
\hline BCAb & $25.1 \pm 0.5^{*}$ & $89 \pm 8 *$ & $>100$ & $347 \pm 1 b$ & $380 \pm 2 a$ & $385 \pm 13 a$ & $69 \pm 1 b$ & $69 \pm 5 b$ & $74 \pm 1 a$ \\
\hline BCPo & $23 \pm 2 c$ & $40 \pm 3 b$ & $56 \pm 1 \mathrm{a}$ & $339 \pm 2 c$ & $355 \pm 2 b$ & $378 \pm 6 a$ & $51 \pm 1 c$ & $57.8 \pm 0.6 b$ & $62 \pm 2 a$ \\
\hline ВСMAb & $>100$ & $31 \pm 1^{*}$ & $69 \pm 3^{*}$ & $>400$ & $>400$ & $>400$ & $>400$ & $>400$ & $>400$ \\
\hline BCMPo & $>100$ & $46 \pm 4$ & $46 \pm 1$ & $>400$ & $>400$ & $>400$ & $>400$ & $>400$ & $>400$ \\
\hline BCEM & $>100$ & $>100$ & $>100$ & $>400$ & $>400$ & $>400$ & $>400$ & $>400$ & $>400$ \\
\hline $\mathrm{BC}$ & $>100$ & $>100$ & $>100$ & $>400$ & $>400$ & $>400$ & $>400$ & $>400$ & $>400$ \\
\hline
\end{tabular}

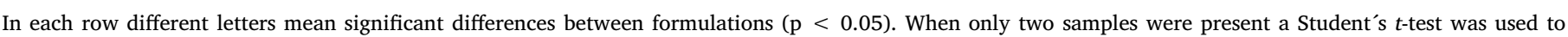
determine the significant difference between two different samples, with $\alpha=0.05$. *Means a significant difference between the samples (p $>0.001$ ).

be conducted at different environmental conditions (temperature and relative humidity) to confirm this observation.

Another interesting potential of bioactive ingredients in cosmeceuticals is their tyrosinase inhibition potential, making them suppressors of melanin that largely contribute to the hyperpigmentation and photoaging (Taofiq et al., 2016a). The search for tyrosinase inhibitors has also intensified in the last decade due to the negative consequences associated with the use of synthetic ingredients that present several negative effects on skin (Taofiq et al., 2017a). In the present study, the results for tyrosinase inhibition activity of the developed formulations are presented in Table 2. For the formulations prepared with mushroom extracts (BCAb and $\mathrm{BCPo}$ ), an anti-tyrosinase activity was observed and the results show that both formulations contain compounds that can inhibit tyrosinase, thus indicating their potential to be used in hyperpigmentation correction formulations. Like what was observed with the antioxidant activity; a gradual loss of tyrosinase inhibition activity from time 0 to 6 months in the formulations prepared with mushroom ethanolic extracts, was observed. This can be attributed to possible interactions with the different ingredients present in the base formulation along time.

The life span of cosmetic and personal care products has been extended using synthetic preservatives due to their broad spectrum of antimicrobial activity, low price and to the fact that these compounds do not origin degradation products that affect physico-chemical properties (colour, pH, viscosity) (Kerdudo et al., 2016). Over the years some of these synthetic preservatives have become more controversial because of some negative effects associated with their use. Bearing in mind these challenges, cosmetic companies are now in search of nonharmful alternatives for consumers, and bioactive compounds with multifunctional properties are slowly been used for this purpose (Taofiq et al., 2017a). In the present study, the antimicrobial activity of each cosmeceutical formulation against Gram-negative, Gram-positive and yeast strains is presented in Table 3 . In all cases, the prepared formulations were found to be effective against Gram-negative, Grampositive bacteria and Candida albicans. However, at the effective minimum inhibitory concentration, the antimicrobial activity failed to be maintained until time 6 months, highlighting a loss of bioactivity of the extracts. However, the results suggest that the compounds present in the studied extracts have the potential to be used as preservatives, capable of preventing microbial contamination in cosmeceutical formulations, but need strategies to increase effectiveness maintenance along storage time.

It was possible to identify and quantify the amount of phenolic acids and related compounds, initially present in the extracts, within each prepared cosmeceutical formulation (Table 3). All the target compounds were stable and there was no significant loss over the storage time from 0 to 6 months. Concerning the bioactive properties, a loss of activity was observed over time, pointing out that other compounds, over the ones analysed in the extracts and formulations, might
Table 3

Phenolic acids and ergosterol content in the developed cosmeceutical formulations.

\begin{tabular}{lllll}
\hline Samples & $\begin{array}{l}\text { Ergosterol, Phenolic acids and Related Compounds in each cosmeceutical } \\
\text { formulation }\end{array}$ \\
\cline { 2 - 5 } & $\begin{array}{l}\text { Cinnamic acid } \\
(\mu \mathrm{g})\end{array}$ & $\begin{array}{l}p \text { - } \\
\text { Hydroxybenzoic } \\
\text { acid }(\mu \mathrm{g})\end{array}$ & $\begin{array}{l}p \text {-Coumaric } \\
\text { acid }(\mu \mathrm{g})\end{array}$ & Ergosterol $(\mathrm{mg})$ \\
& & & \\
\hline BCAbT0 & $2.20 \pm 0.07 \mathrm{a}$ & nd & nd & $1.11 \pm 0.01 \mathrm{a}$ \\
BCAbT3 & $2.19 \pm 0.07 \mathrm{a}$ & nd & nd & $1.10 \pm 0.01 \mathrm{a}$ \\
BCAbT6 & $2.18 \pm 0.03 \mathrm{a}$ & nd & nd & $1.08 \pm 0.01 \mathrm{a}$ \\
BCPOT0 & $8.84 \pm 0.02^{\mathrm{a}}$ & $3.87 \pm 0.02 \mathrm{a}$ & $1.52 \pm 0.02 \mathrm{a}$ & $1.93 \pm 0.01 \mathrm{a}$ \\
BCPoT3 & $8.82 \pm 0.14^{\mathrm{a}}$ & $3.84 \pm 0.06 \mathrm{a}$ & $1.51 \pm 0.07 \mathrm{a}$ & $1.92 \pm 0.03 \mathrm{a}$ \\
BCPoT6 & $8.80 \pm 0.03^{\mathrm{a}}$ & $3.80 \pm 0.07 \mathrm{a}$ & $1.50 \pm 0.02 \mathrm{a}$ & $1.89 \pm 0.03 \mathrm{a}$ \\
\hline
\end{tabular}

In each column different letters mean significant differences in bioactive compounds content between formulations $(\mathrm{p}<0.05)$.

contribute for their bioactivity.

\subsection{Bioactivity of mushroom-based cosmeceutical formulations -real time in vitro release of microencapsulated extracts}

Real time in vitro release of bioactive compounds from polymeric microspheres is typically done to evaluate control release at appropriate environmental and physiological conditions. This process may, sometimes, take weeks, months, or even years (Andhariya et al., 2017b). The real time in vitro release of the mushroom extracts loaded in the prepared microparticles, was performed under controlled temperature during a 6-month period. The microparticles prepared in the present work showed high encapsulation efficiencies and the manifestation of bioactivity, due to compounds release from the microparticles, was evaluated on the base cream added with microencapsulated extracts. From the obtained results, it can be seen that the formulations prepared with BCMAb and BCMPo particles, respectively, did not display significant antioxidant and antimicrobial effects up to month 6 , which can be due to a very slow release of the encapsulated bioactives, whose concentration is not enough to exert a bioactive effect. The slow release, makes the process suitable to be used in the design of cosmeceutical formulations, whose shelf life span varies from months to even years.

Therefore, the gradual release ensures a continuous effectiveness against microbial growth. However, and from the point of view of skin beneficial effects, their slow release can be disadvantageous as the formulated product may not release the bioactive compounds at the required levels for the intended effect. Nevertheless, it is expected that the application process of the cream favour mechanical disruption of the capsules, and thus the prompt release of the protected bioactive compounds on skin surface.

As regards the anti-tyrosinase activity, the released compounds 


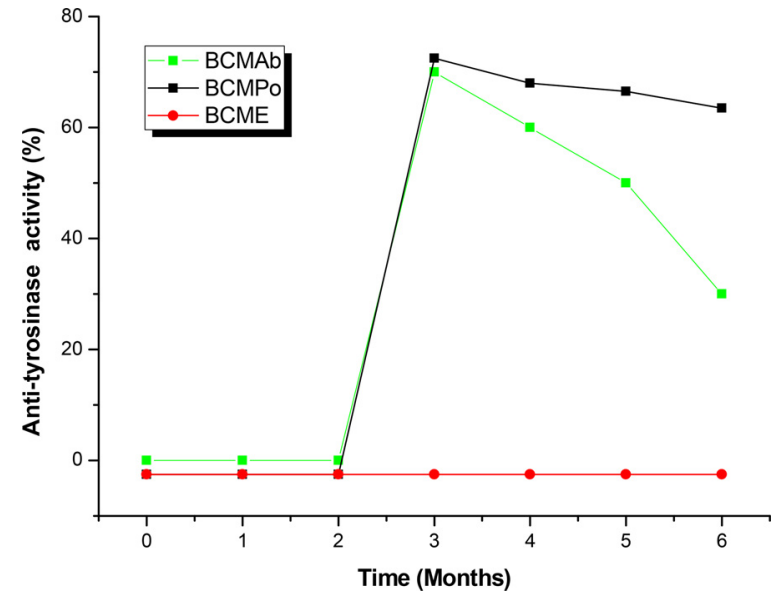

Fig. 4. Extrapolated real time in vitro release profile of formulations designed with microparticles (BCMAb- base cream with microparticles of A. bisporus extract, BCMPo- base cream with microparticles of $P$. ostreatus extract and BCEM- base cream with empty microparticles (control)).

were sufficient to cause activity manifestation of the formulations at the $3^{\text {rd }}$ month of storage, as shown in Table 2 . From the anti-tyrosinase bioactivity evolution profile presented in Fig. 4, it can be observed that both formulations, BCMAb and BCMPo, showed comparable patterns until the $3^{\text {rd }}$ month of storage time (no bioactivity). After this timeperiod they start to reveal significant activity (31 \pm 1 and $46 \pm 4 \mathrm{mg}$ / $\mathrm{mL}$, for BCMAb and BCMPo respectively) but with a decreasing profile until the 6 months. In particular, BCMPo was able to maintain a more sustained release (no significant decrease was observed), comparatively with BCMAb that showed an important decrease up to the $6^{\text {th }}$ month. As expected BCEM did not show any contribution to the tested bioactivities. The results for the antimicrobial activity of each prepared formulation are presented in Table 4. Most studies on bioactive compounds release, consider various conditions such as temperature, solvent, $\mathrm{pH}$, presence of enzymes or even stirring rate (Burgess and Shen, 2012). However, some of these conditions do not mimic the real environment, or the mechanism behind the release, making the realtime release evaluation, such as the assays done in the present work, an important contribute despite the long time required. In what concerns release profiles evaluation, Acosta et al. (2015) reported that the release of polyphenols from olive extract microencapsulated with chitosan was $\mathrm{pH}$ dependent, and the release rate at $\mathrm{pH} 7.4$ doubled the one obtained at $\mathrm{pH}$ 5.5. Hence, more studies need to be conducted to find the best conditions that might promote the degradation of the polymeric material allowing for a faster delivery of the bioactive compounds, when applied.

\subsection{Physico-chemical parameters}

During product development, especially when bioactive ingredients are added either to improve products shelf life or to functionalise the formulations, several procedures need to be conducted to ascertain the safety and efficacy of the product. Some of the preliminary tests include $\mathrm{pH}$, viscosity, colour and odour evaluation. Current cosmetic market offers consumers a wide variety of choices; even numerous consumers still prefer products with basic colour. Hence, cosmetics companies have paid attention in managing colour display during product design. In the present study, the evaluation of the physical and chemical stability of the prepared semisolid formulations in terms of $\mathrm{pH}$ and colour was carried out during the storage period up to 6 months. Table 5 summarizes the $\mathrm{pH}$ values of each formulation and the behaviour in terms of colour changes. Over the course of incubation, no significant colour changes were observed suggesting that the compounds present in the extracts were stable and their possible degradation did not lead to

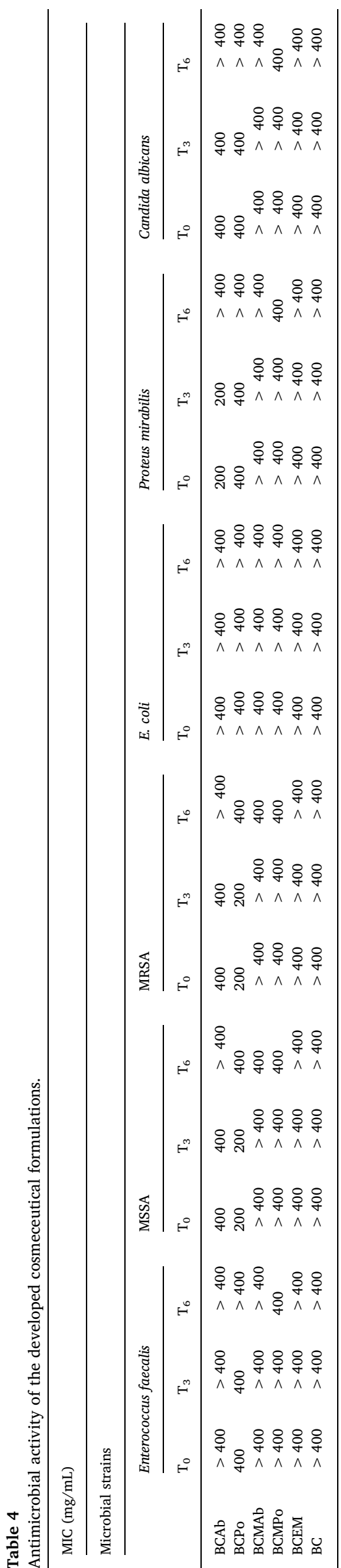


products imparting colour changes. From data on Table 5, it is possible to conclude that the formulations incorporated with the mushroom ethanolic extracts (BCAb and BCPo) presented lower level of lightness $\left(l^{*}\right)$ as the storage time increase, and this may be due to oxidation of the incorporated extracts. The colour coordinates for the formulations prepared with microparticles revealed a deeper red (greater $a^{*}$ value) mainly due to the contribution of alginate. Overall, the initial odour and colour were maintained and without significant variations over the course of storage, and these are crucial parameters during preliminary stability testing analysis.

The rate of dermal absorption of topical formulations such as lotions and creams are often influenced by the $\mathrm{pH}$ of the product. The skin surface $\mathrm{pH}$ is around 5.5, and at this condition, the skin micro-flora is maintained (Ali and Yosipovitch, 2013; Martínez-Pla et al., 2004). Most reports have suggested that a pH between 3.5 and 6.5 can be considered for cosmetic formulations because most of the pathogenic bacteria, such as Staphylococcus aureus, thrive best at neutral $\mathrm{pH}$ levels (Ali and Yosipovitch, 2013). In the present work, all the cosmeceutical formulations presented a pH between 3.4 and 5.0 suggesting that these formulations have a large $\mathrm{pH}$ range, that was maintained even after months under storage. Samples were stored at $4{ }^{\circ} \mathrm{C}$ and the lack of a significant $\mathrm{pH}$ variations is a clear indication of formulation stability. However, because most of the products exhibit excellent stability at this temperature, temperature variation studies are necessary at $50^{\circ}, 25^{\circ} \mathrm{C}$ and $-10{ }^{\circ} \mathrm{C}$ in order to fulfil the cycle stability tests and to evaluate the behaviour of the developed formulations under temperature stress (Moraes and Ueoka, 2018).

\section{Conclusion}

Bioactive compounds from natural sources are considered to show interesting bioactive properties that tend to affect skin structure and function, and as such, it is necessary to develop effective biocompatible/biodegradable systems to ensure topical delivery of these natural active ingredients. The above findings reveal that ethanolic extracts of $A$. bisporus and $P$. ostreatus, display strong antioxidant, antimicrobial and anti-tyrosinase activities, mainly due to the contribution of their bioactive components, being suitable as multifunctional cosmeceutical ingredients. The atomization/coagulation technique was successfully applied to encapsulate the bioactives. After incorporating of the extracts into the base cosmetic cream, they displayed bioactivity; even with a decreasing pattern along the 6 months, for the free extracts. For the microencapsulated extracts, no demonstration of significant antioxidant and antimicrobial activity was observed, with anti-tyrosinase bioactivity being displayed after 3 months. Key findings in the present study revealed that it is important to study the release profile of the bioactive compounds from the microspheres, under different environmental conditions, in order to promote a faster release of the active ingredient, which might be interesting for certain applications. Results presented in the present work reveal the promising potential of mushroom extracts in what concerns bioactivity and stability, hence, studies related with in vitro skin permeation using models to determine topical bioavailability of these bioactive ingredients will be conducted in future work.

\section{Conflicts of interest}

No conflict of interest.

\section{Acknowledgments}

The authors are grateful to the Foundation for Science and Technology (FCT, Portugal) and FEDER under Programme PT2020 for financial support to CIMO (UID/AGR/00690/2013) and S.A. Heleno (SFRH/BPD/101413/2014). This work was also financially supported by Project POCI-01-0145-FEDER-006984 - Associate Laboratory LSRE- 
LCM funded by FEDER through COMPETE2020 - Programa Operacional Competitividade e Internacionalização (POCI) - and by national funds through FCT and project NORTE-01-0145-FEDER-000006, supported by Norte Portugal Regional Operational Programme (NORTE 2020), under the Portugal 2020 Partnership Agreement, through the European Regional Development Fund (ERDF). The authors are grateful to FEDER-Interreg España-Portugal programme for financial support through the project 0377_Iberphenol_6_E. This work was also funded by the European Structural and Investment Funds (FEEI) through the Regional Operational Program North 2020, within the scope of Mobilizing Project ValorNatural ${ }^{\circledR}$. This work is funded by the European Agricultural Fund for Rural Development (EAFRD), through the Rural Development Program (PDR2020), within the scope of Project MicoCoating (PDR2020-101-031472).

\section{Appendix A. Supplementary data}

Supplementary material related to this article can be found, in the online version, at doi:https://doi.org/10.1016/j.indcrop.2018.07.057.

\section{References}

Acosta, N., Sanchez, E., Calderon, L., Cordoba-Diaz, M., Cordoba-Diaz, D., Dom, S., Heras, A., 2015. Physical stability studies of semi-solid formulations from natural compounds loaded with Chitosan Microspheres. Mar. Drugs 13, 5901-5919. https://doi. org/10.3390/md13095901.

Ali, S.M., Yosipovitch, G., 2013. Skin pH: from basic science to basic skin care. Acta Derm. Venereol. 93, 261-267. https://doi.org/10.2340/00015555-1531.

Andhariya, J.V., Choi, S., Wang, Y., Zou, Y., Burgess, D.J., Shen, J., 2017a. Accelerated in vitro release testing method for naltrexone loaded PLGA microspheres. Int. J. Pharm. 520, 79-85. https://doi.org/10.1016/j.ijpharm.2017.01.050.

Andhariya, J.V., Choi, S., Wang, Y., Zou, Y., Burgess, D.J., Shen, J., 2017b. Accelerated in vitro release testing method for naltrexone loaded PLGA microspheres. Int. J. Pharm. 520, 79-85. https://doi.org/10.1016/j.ijpharm.2017.01.050.

Barboza, F.M., Machado, W.M., Olchanheski Junior, L.R., Padilha De Paula, J., Zawadzki, S.F., Fernandes, D., Farago, P.V., 2014. PCL/PHBV microparticles as innovative carriers for oral controlled release of manidipine dihydrochloride. Sci. World J. 2014. https://doi.org/10.1155/2014/268107.

Bishop, K.S., Kao, C.H.J., Xu, Y., Glucina, M.P., Paterson, R.R.M., Ferguson, L.R., 2015. From 2000 years of Ganoderma lucidum to recent developments in nutraceuticals. Phytochemistry 114, 56-65. https://doi.org/10.1016/j.phytochem.2015.02.015.

Bissett, D.L., 2009. Common cosmeceuticals. Clin. Dermatol. 27, 435-445. https://doi. org/10.1016/j.clindermatol.2009.05.006.

Burgess, D.J., Shen, J., 2012. Accelerated in vitro release testing methods for extended release parenteral dosage form. J. Pharm. Pharmacol. 64, 986-996. https://doi.org/ 10.1111/j.2042-7158.2012.01482.x.

Caleja, C., Ribeiro, A., Barros, L., Barreira, J.C.M., Antonio, A.L., Oliveira, M.B.P.P., Barreiro, M.F., Ferreira, I.C.F.R., 2016. Cottage cheeses functionalized with fennel and chamomile extracts: comparative performance between free and microencapsulated forms. Food Chem. 199, 720-726. https://doi.org/10.1016/j foodchem.2015.12.085.

Caleja, C., Barros, L., Antonio, A.L., Oliveira, M.B.P.P., Ferreira, I.C.F.R., 2017. A comparative study between natural and synthetic antioxidants: evaluation of their performance after incorporation into biscuits. Food Chem. 216, 342-346. https://doi. org/10.1016/j.foodchem.2016.08.075.

Casanova, F., Estevinho, B.N., Santos, L., 2016. Preliminary studies of rosmarinic acid microencapsulation with chitosan and modified chitosan for topical delivery. Powder Technol. 297, 44-49. https://doi.org/10.1016/j.powtec.2016.04.014.

dos Santos, P.P., Flores, S.H., de Oliveira Rios, A., Chiste, R.C., 2016. Biodegradable polymers as wall materials to the synthesis of bioactive compound nanocapsules. Trends Food Sci. Technol. 53, 23-33. https://doi.org/10.1016/j.tifs.2016.05.005.

Gezina, S.F.W.Gerber, Lizelle, T.Fox, Minja, Gerber, du Preez, Jan L., van Zyl, Sterna, Boneschans, Banie, du P, J., 2015. Stability, clinical efficacy, and antioxidant properties of Honeybush extracts in semi-solid formulations. Pharmacogn. Mag. 11, 337-351.

Heleno, S.A., Barros, L., Martins, A., Queiroz, M.J.R.P., Santos-Buelga, C., Ferreira, I.C.F.R., 2012. Fruiting body, spores and in vitro produced mycelium of Ganoderma lucidum from Northeast Portugal: a comparative study of the antioxidant potential of phenolic and polysaccharidic extracts. Food Res. Int. 46, 135-140. https://doi.org/ 10.1016/j.foodres.2011.12.009.

Heleno, S.A., Martins, A., Queiroz, M.J.R.P., Ferreira, I.C.F.R., 2015. Bioactivity of phenolic acids: metabolites versus parent compounds: a review. Food Chem. 173, 501-513. https://doi.org/10.1016/j.foodchem.2014.10.057.

Kerdudo, A., Burger, P., Merck, F., Dingas, A., Rolland, Y., Michel, T., Fernandez, X., 2016. Development of a natural ingredient - natural preservative: a case study. Comptes Rendus Chim. 19, 1077-1089. https://doi.org/10.1016/j.crci.2016.06.004.

Martínez-Pla, J.J., Martín-Biosca, Y., Sagrado, S., Villanueva-Camañas, R.M., MedinaHernández, M.J., 2004. Evaluation of the $\mathrm{pH}$ effect of formulations on the skin permeability of drugs by biopartitioning micellar chromatography. J. Chromatogr. A 1047, 255-262. https://doi.org/10.1016/j.chroma.2004.07.011.

Miyake, M., Yamamoto, S., Sano, O., Fujii, M., Kohno, K., Ushio, S., Iwaki, K., Fukuda, S., 2010. Inhibitory effects of 2-Amino-3 H -phenoxazin-3-one on the melanogenesis of murine B16 melanoma cell line. Biosci. Biotechnol. Biochem. 74, 753-758. https:// doi.org/10.1271/bbb. 90795 .

Money, N.P., 2016. Are mushrooms medicinal? Fungal Biol. 120, 449-453. https://doi. org/10.1016/j.funbio.2016.01.006.

Moraes, C.A.P., Ueoka, A.R., 2018. Development and stability evaluation of liquid crystalbased formulations containing glycolic plant extracts and nano-actives. Cosmetics 5 , 1-7. https://doi.org/10.3390/cosmetics5020025.

Papadimitriou, S., Bikiaris, D., 2009. Novel self-assembled core-shell nanoparticles based on crystalline amorphous moieties of aliphatic copolyesters for efficient controlled drug release. J. Control. Release 138, 177-184. https://doi.org/10.1016/j.jconrel. 2009.05.013.

Reis, F.S., Lima, R.T., Morales, P., Ferreira, I.C.F.R., Vasconcelos, M.H., 2015. Methanolic extract of ganoderma lucidum induces autophagy of AGS human gastric tumor cells. Molecules 20, 17872-17882. https://doi.org/10.3390/molecules201017872.

Secchi, M., Castellani, V., Collina, E., Mirabella, N., Sala, S., 2014. Assessing eco-innovations in green chemistry: Life Cycle Assessment (LCA) of a cosmetic product with a bio-based ingredient. J. Clean. Prod. 129, 269-281. https://doi.org/10.1016/j. jclepro.2016.04.073.

Taofiq, O., Calhelha, R.C., Heleno, S., Barros, L., Martins, A., Santos-Buelga, C., Queiroz, M.J.R.P., Ferreira, I.C.F.R., 2015. The contribution of phenolic acids to the anti-inflammatory activity of mushrooms: screening in phenolic extracts, individual parent molecules and synthesized glucuronated and methylated derivatives. Food Res. Int. 76, 821-827. https://doi.org/10.1016/j.foodres.2015.07.044.

Taofiq, O., González-Paramás, A.M., Martins, A., Barreiro, M.F., Ferreira, I.C.F.R., 2016a. Mushrooms extracts and compounds in cosmetics, cosmeceuticals and nutricosmetics-a review. Ind. Crops Prod. 90, 38-48. https://doi.org/10.1016/j. indcrop.2016.06.012.

Taofiq, O., Heleno, S., Calhelha, R., Alves, M., Barros, L., Barreiro, M., González-Paramás, A., Ferreira, I., 2016b. Development of mushroom-based cosmeceutical formulations with anti-inflammatory, anti-tyrosinase, antioxidant, and antibacterial properties. Molecules 21, 1372. https://doi.org/10.3390/molecules21101372.

Taofiq, O., Martins, A., Barreiro, M.F., Ferreira, I.C.F.R., 2016c. Anti-inflammatory potential of mushroom extracts and isolated metabolites. Trends Food Sci. Technol. 50, 193-210. https://doi.org/10.1016/j.tifs.2016.02.005.

Taofiq, O., González-paramás, A.M., Barreiro, M.F., Ferreira, I.C.F.R., 2017a. hydroxycinnamic acids and their derivatives cosmeceutical significance, challenges and future perspectives, a review. Molecules 22, 1-24. https://doi.org/10.3390/ molecules22020281.

Taofiq, O., Heleno, S.A., Calhelha, R.C., Alves, M.J., Barros, L., González-Paramás, A.M., Barreiro, M.F., Ferreira, I.C.F.R., 2017b. The potential of Ganoderma lucidum extracts as bioactive ingredients in topical formulations, beyond its nutritional benefits. Food Chem. Toxicol. 108, 139-147. https://doi.org/10.1016/j.fct.2017.07.051. 